\title{
sciendo
}

\author{
SEBASTIAN SAWONIK ${ }^{1}$, MONIKA KOZŁOWIEC ${ }^{1}$, ALEKSANDRA KOŁODYŃSKA ${ }^{1}$, \\ ADAM DOMAGAŁA ${ }^{1}$, ANNA AFTYKA ${ }^{2}$, JOANNA MILANOWSKA ${ }^{3}$, PATRYCJA GIERSZON ${ }^{3}$, \\ MARIA DOROTA KWIKA ${ }^{4}$, MARZENA SAMARDAKIEWICZ ${ }^{3}$
}

\section{Do medical students have problem with choosing the specialty? Preliminary report of the medical students population based study}

\begin{abstract}
Introduction. Choosing medical specialty is one of the most crucial decisions about future career of graduates. Multiplicity and variety of available options make great opportunities for development of interests and ambitions of future doctors. Unfortunately, it can also be an impediment in making decisions about path of medical career.

Aim. The aim of the study was to discover if medical students have problem with choosing specialty and to ask about availability and need of career guidance for medical students.

Material and methods. Voluntary survey was conducted via the Internet among medical students in Polish and foreign medical universities.

Results. The total number of 565 medical students completed the survey -371 women $(66.5 \%)$ and 189 men $(33.5 \%)$. They were students of 16 medical universities, 10 Polish and 6 foreign ones. Problem with choosing medical specialization reported over $70 \%$ respondents. Only $11.9 \%$ of the group declare that they participated in classes that were helpful in making decision about their future medical career. Need for career guidance was revealed in over $91.5 \%$ answers. Significant difference between genders has been found in reporting problem with choosing medical specialty - it was reported by $75.5 \%$ of women and $62.4 \%$ of men. There were no differences between the Polish and foreign students and between students in different years of study in all the questioned issues - choice of medical specialization, participation in classes which were helpful in decision making and necessity of counseling in choosing specialization.

Conclusion. The results of the study clearly indicate that most of medical students have problem with choosing medical specialty. Guidance is not realized among most of students, despite the fact that the vast majority of them reports need for that kind of consultation.
\end{abstract}

Keywords: choosing of medical specialty, medical students, career counseling.

DOI: $10.2478 /$ pjph-2018-0022

\section{INTRODUCTION}

Choosing medical specialty is one of the most crucial decisions about future career of graduates. The nature of their future medical practice depends on the path that the students resolve to follow [1]. The medical specialties differ greatly in work settings, skill sets, duties, responsibilities and professional interests, so that they essentially constitute a group of distinct occupations [2,3]. The individual generally gathers information about a number of careers from a variety of objective and subjective sources to form an opinion of the occupation [4].

Authors have already searched publications about professional guidance in choosing medical career and the need of this type of counseling. Unfortunately only few research of this topic were found. Researches proving the need for career guidance were performed in Nigeria [5] and Gambia [6]. Many articles about factors that influence students decisions [1,7] and about personality of medical students $[1,6,8]$ have been found. Some of them raised a subject of sociodemographic factors [9], and the needs of society [10]. Gender differences and its implications in choosing specialty were also widely discussed in a high number of publications $[11,12]$. Despite the fact that the need of professional counseling in choosing medical specialty is present, there is a lack of articles that state this requirement. Authors wanted to emphasize this necessity.

It seems reasonable to encourage the medical students to make decision about their specialty wisely, considering all factors that can influence their satisfaction and success in future career. According to studies, in the United States only $12 \%$ of physicians expressed their extreme satisfaction with their work, $48 \%$ of the respondents showed great satisfaction, $34 \%$ of the people turned out to be only quite satisfied, $5 \%$ of them responded to be not very satisfied, $1 \%$ of the group described

${ }^{1}$ Department of Pediatric Hematology, Oncology and Transplantology, II Faculty of Medicine with English Language Division, Medical University of Lublin, Poland

${ }^{2}$ Department of Anaesthesiological and Intensive Care Nursing, Faculty of Health Sciences, Medical University of Lublin, Poland

${ }^{3}$ Department of Applied Psychology, II Faculty of Medicine with English Language Division, Medical University of Lublin, Poland

${ }^{4}$ The State School of Higher Education (PWSZ) in Zamość, Poland 
themselves as dissatisfied" [13]. Due to the fact that in the USA there is amplified system of guidance this percentage is not very optimistic and can be even worse in Poland (because of lack of similar system in medical universities). These data could be enlarged by counseling in making mentioned decisions.

According to Holland's congruence theory, the choice of the career is an expression of personal nature shared by all professionals of the same kind [1], what leads to the conclusion that the choice of medical specialty should be guided in a professional way - offered by universities or student's associations. Analogic counseling in other fields (also in native background), like choosing an University, or choosing a job shows that professional guidance is necessary to improve the percentage of satisfied people with their work. Moreover, several observations suggest that a physician's professional satisfaction may have an important effect on patient satisfaction [1]. Professional guidance in choosing medical specialty should contain an information about society requirements of a higher number of specialists in one medical branch and the lower need of educating in another. Furthermore, the current instability of the labor market structure of medical specialists can lead to problems in access to care and come out as consequence of unsatisfactory quality and higher cost of medical care [14]. Graduates who choose popular but not desired specialty will meet higher level of competitiveness. What is more, incongruity between society demands and doctors' supply generate higher costs in education, treatment and function of health care system. On account of medical educational costs, students prefer to get although less costly education, but more profitable as far as earnings are concerned. Such a tendency will negatively influence health care availability as well as accessibility and cost [15].

Gender differences in physical and mental predispositions make another field of discussion. Swedish research states that women, by contrast to men, were motivated by number of working hours concerning work and family [8]. Furthermore another study from the Kingdom of Saudi Arabia continues that men stood out with 'impulsive sensation seeking', however students choosing a surgery specialty placed the highest level on the scale as far as 'impulsive sensation seeking', 'neuroticism-anxiety', 'aggression-hostility' and 'sociability' are concerned [14]. Due to these gender implications women and men usually choose different specialties. The research of the Gambian students states that the majority of women chose Obstetrics/Gynaecology, Paediatrics and Surgery as a specialty, however men opted to Internal Medicine, Surgery and Obstetrics/Gynaecology [15]. These data make another reason for setting up a system of professional counseling for students and young doctors.

The good example of a tool in professional counseling in choosing specialization is so called The Goo Tolerance Index. It was based on three assumptions. The first says that a lot of goo is involved in the medicine practice. The second premise believes that goo is appalling. Thirdly, goo tolerance is one of the best predictors. Students from Sydney as first could rate their own tolerance to go on 1-10 scale. After that, they compared their results with Gooiness Reference of Selected Specialties Scale. In this way they could find what specialty is the most appropriate for them. In connection with that specialties are divided into three groups: Low-goo specialties (Psychiatry, Radiology etc.); Moderate-goo specialties (Family medicine, Internal medicine, Paediatrics etc.), High-goo specialties (Surgical specialties, Emergency medicine etc.) and Extreme-goo specialties (Pathology) [16]. Similar instrument should be given for Polish students to optimize their achievements in the future career and make this crucial decision easier.

\section{AIM}

The aim of the study was to analyze the necessity of counseling in making choice of suitable specialization in medical student's opinion. Furthermore, we wanted to emphasize the importance of guidance in choosing medical specialty.

\section{MATERIAL AND METHODS}

The study involves a survey which was conducted on a group of 565 medicine students. Respondents are studying at 16 Medical Universities, ten Polish ones (Białystok, Gdańsk, Katowice, Kielce, Kraków, Lublin, Łódź, Olsztyn, Poznań, Warszawa) and six foreign ones (Bologna, Chiang Mai, Gomel, Grodno, Ljubljana, Minsk). Number of respondents were respectively, $\mathrm{N}=486$ in Poland, and $\mathrm{N}=79$ abroad.

Participation in the research was absolutely voluntary and prosecuted via the Internet way. Interviewees have answered eight questions: "1. Sex. 2. Age. 3. Year of study. 4. University, city. 5. Have you ever had any problem with choosing medical specialization? 6. Have you ever participated in classes, where the problem of choosing specialization was introduced? 7. Do you think that students of medicine need guidance in choosing specialization?" [12]. The questions regarding the choice of specialization were dichotomous - the respondents had a choice of "yes or no" answer. The protocol study was approved by the Ethics Committee of the Medical University of Lublin no. KE-0254/15/2017.

\section{Statistical analysis}

The statistical evaluation of the results was carried out using the program IBM SPSS 21. Qualitative variables were characterized using numerousness and percentage. Quantitative variables were analyzed using mean and standard deviation. Chi2 test was used to assessment inequalities between different groups. As many as $95 \%$ confidence intervals were taken. Statistical significance was determined by $\mathrm{p}$ value $<0.05$.

\section{RESULTS}

In the study 565 medical students took part, including 371 women $(66.5 \%)$ and 189 men $(33.5 \%)$. The respondents were between 18 and 30 years old, their medium age was almost 23 years old ( $M=22.7, S D=2)$. The majority of respondents were from Poland $(86 \%)$ and there were 79 students from abroad. The biggest groups of interviewees were students of: sixth year of medicine $(\mathrm{n}=161,28.5 \%)$, second year of medicine $(\mathrm{n}=158$, $28 \%$ ), as well as fifth year of medicine $(n=143,25.3 \%)$. Respondents were studying at 16 Medical Universities. The characteristic of analyzed group is presented in Table 1.

Problem with choice of medical specialization had over $70 \%$ respondents $(n=399,71.1 \%)$. Participation in classes, which were helpful in making decision was declared by only one in every ten students $(n=67,11.9 \%)$. The necessity of counseling in making choice of medical specialization was reported by over $90 \%$ of respondents $(\mathrm{n}=571,91.5 \%)$ - Table 2 . 
TABLE 1. The demographic representation of studied medical students population.

\begin{tabular}{|c|c|c|c|}
\hline \multicolumn{2}{|c|}{ Variable } & $\mathbf{N}$ & $\%$ \\
\hline \multirow{2}{*}{ Sex } & Women & 371 & 66.5 \\
\hline & Men & 189 & 33.5 \\
\hline \multirow{2}{*}{ Nationality } & Polish & 486 & 86.0 \\
\hline & Other & 79 & 14.0 \\
\hline \multirow{6}{*}{ Year of the study } & 1 & 8 & 1.4 \\
\hline & 2 & 158 & 28.0 \\
\hline & 3 & 39 & 6.9 \\
\hline & 4 & 55 & 9.7 \\
\hline & 5 & 143 & 25.3 \\
\hline & 6 & 161 & 28.5 \\
\hline \multirow{6}{*}{ University } & Białystok & 74 & 13.1 \\
\hline & Ljublana & 67 & 11.9 \\
\hline & Lublin & 224 & 39.6 \\
\hline & Poznań & 40 & 7.1 \\
\hline & Warszawa & 142 & 25.1 \\
\hline & Others & 18 & 3.2 \\
\hline
\end{tabular}

TABLE 2. The necessity of counseling in making choice of suitable specialization in medical student's opinion.

\begin{tabular}{lcc}
\hline \hline \multicolumn{1}{c}{ Issues } & $\mathbf{N}$ & $\mathbf{\%}$ \\
\hline Problem with choice of medical specialization & 399 & 71.1 \\
\hline Participation in classes which are helpful in making decision & 67 & 11.9 \\
\hline The necessity of counseling in making choice of specialization & 517 & 91.5 \\
\hline
\end{tabular}

TABLE 3. The necessity of counseling in making choice of specialization in women and men's opinion.

\begin{tabular}{|c|c|c|c|c|c|c|}
\hline \multirow{3}{*}{ Issues } & \multicolumn{4}{|c|}{ Sex } & \multirow{3}{*}{$\chi^{2}$ Test } & \multirow{3}{*}{$\mathbf{p}$} \\
\hline & \multicolumn{2}{|c|}{$\begin{array}{l}\text { Women } \\
(n=376)\end{array}$} & \multicolumn{2}{|c|}{$\begin{array}{c}\text { Men } \\
(n=189)\end{array}$} & & \\
\hline & $\mathbf{n}$ & $\%$ & $\mathbf{n}$ & $\%$ & & \\
\hline Problem with choice of specialization & 283 & 75.5 & 116 & 62.4 & $\chi^{2}=10.39$ & 0.002 \\
\hline $\begin{array}{l}\text { Participation in classes which } \\
\text { are helpful in making decision }\end{array}$ & 43 & 11.4 & 24 & 12.7 & $\chi^{2}=0.19$ & 0.680 \\
\hline $\begin{array}{l}\text { The necessity of counseling } \\
\text { in making choice of specialization }\end{array}$ & 394 & 92.8 & 168 & 88.9 & $\chi^{2}=2.49$ & 0.149 \\
\hline
\end{tabular}

TABLE 4. The necessity of counseling in making choice of specialization in Polish and foreign students' opinion.

\begin{tabular}{|c|c|c|c|c|c|c|}
\hline \multirow{3}{*}{ Issues } & \multicolumn{4}{|c|}{ Nationality } & \multirow{3}{*}{$\chi^{2}$ Test } & \multirow{3}{*}{$\mathbf{p}$} \\
\hline & \multicolumn{2}{|c|}{$\begin{array}{l}\text { Poland } \\
(n=486)\end{array}$} & \multicolumn{2}{|c|}{$\begin{array}{l}\text { Other } \\
(n=79)\end{array}$} & & \\
\hline & $\mathbf{n}$ & $\%$ & $\mathbf{n}$ & $\%$ & & \\
\hline $\begin{array}{l}\text { The problem with choice of } \\
\text { specialization }\end{array}$ & 344 & 71.2 & 55 & 70.5 & $\chi^{2}=.016$ & 0.893 \\
\hline $\begin{array}{l}\text { Participant in classes which } \\
\text { are helpful in making decision }\end{array}$ & 61 & 12.6 & 6 & 7.6 & $\chi^{2}=1.597$ & 0.261 \\
\hline $\begin{array}{l}\text { The necessity of counseling } \\
\text { in making choice of specialization }\end{array}$ & 445 & 91.6 & 72 & 91.1 & $\chi^{2}=.016$ & 0.830 \\
\hline
\end{tabular}

It is showed that women significantly more often than men had problems with choice of medical specialization: it is suitable reported by $75.5 \%$ of women and $62.4 \%$ of men $\left(\chi^{2}=10.390,0.002\right)$. On the other hand, more than half of men also had difficulties with choosing specialty. At the same time, studies have shown lack of differences in participation in classes, which are helpful in making choice of specialization and in necessity of counseling in making choice of specialization between respondents of different sex - Table 3 .

No differences were found in reporting problem with choice of medical specialization, participation in classes, which are helpful in making decision and necessity of counseling in making choice of specialization between Polish students and students from other countries - Table 4.

There were no differences in a group of Polish students and between students from different years of study in having problem with choice of specialization and the necessity of counseling in making choice of specialization. The frequency of participation in classes helpful in making decision was various in the groups of students from different years of study. Statistical relevance is about limit value $\left(\chi^{2}=9.39, p=0.03\right)$ - Table 5 .

\section{DISCUSSION}

Referred data confirm the need of professional guidance in making choice of specialization. This problem was described in foreign publications but not at all in Polish ones. Similar problem was discussed in Nigerian study. The great number of students did not have any career counseling during medical studies. There is a demand for such kind of assistance for future doctors and it should be adjusted to the national health needs [9]. The percentage of attendance in classes helping in choosing medical specialty in other African countries looks similar to Poland. The results of a study revealed that in South Africa, $54 \%$ of students had no form of career guidance during their medical studies, while in Gambia the number of them amounted to $90 \%$ [10]. In this work comparable data is presented. Only $12.6 \%$ of Polish medicine students have already participated in classes helpful in choosing medical specialty.

In Polish bibliography we can find papers about nurse profession and its demands. Although being a good employer is stimulated by many factors, prosocial motivation prevails over the self - centered one [2]. We can refer these findings to all of medical faculties. On the other hand, different branches of medicine demands from the doctor various attributes of personality and various motivation [3]. Our work proves that students of medicine have problem with choosing their future carrier and need a professional guidance to distinguish necessary qualities in many fields of medicine.

These data can be easily found in foreign publications. Higher humanistic ratings were given for the students who chose primary care or surgical specialties; lower, however, were for those who chose the support specialties [4].

TABLE 5. The necessity of counseling in making choice of specialization in opinion of students from different years of study.

\begin{tabular}{|c|c|c|c|c|c|c|c|c|c|c|}
\hline & \multicolumn{8}{|c|}{ Year of study } & \multirow{3}{*}{$\begin{array}{l}\text { Statistics of } \\
\text { the test }\end{array}$} & \multirow{3}{*}{$\mathbf{p}$} \\
\hline & \multicolumn{2}{|c|}{$1-2(n=166)$} & \multicolumn{2}{|c|}{$3-4(n=94)$} & \multicolumn{2}{|c|}{$5(n=143)$} & \multicolumn{2}{|c|}{$6(n=161)$} & & \\
\hline & $\mathbf{n}$ & $\%$ & $\mathbf{n}$ & $\%$ & $\mathbf{n}$ & $\%$ & $\mathbf{n}$ & $\%$ & & \\
\hline The problem with choice of specialization & 117 & 70.5 & 64 & 68.1 & 107 & 74.8 & 110 & 68.8 & $\chi^{2}=1.92$ & 0.59 \\
\hline Participant in classes which are helpful in making decision & 15 & 9.0 & 19 & 20.2 & 12 & 8.4 & 21 & 13.0 & $\chi^{2}=9.39$ & 0.03 \\
\hline The necessity of counseling in making choice of specialization & 159 & 95.8 & 85 & 90.4 & 129 & 90.2 & 144 & 89.4 & $\chi^{2}=5.31$ & 0.15 \\
\hline
\end{tabular}


In authors' opinion, desired personality traits in various specializations should be examined and put to counselors.

In the field of nonmedical branches of labour market we can find a list of Polish institutions offering job counseling (schools, psychological - pedagogical dispensaries, employment agencies etc.). In other countries similar institutions could be found as well. The Department for Education in the UK published guidelines in job counseling. Nowadays, career guidance is based not only on giving advice but also on giving inspiration and aspiration for students. Permanent and diverse contact with representatives of the various specialties or different academic and professional institutions can give students motivation to develop themselves and encourage to gain new educational experiences and prospects, as well as to think outside the box referring to their future career paths [5]. Authors find the requirement of analogical initiatives in the field of medical specialties.

The American study of Missouri high schools shows the effectiveness and the need of similar counseling programs students from universities which were offering career guidance, achieved better and higher education, and were better prepared for future career [6].

Furthermore, the patients of physicians with higher professional satisfaction may themselves be more satisfied with their care. This hypothesis was proved by the American study. It was presented that physicians who described themselves as very or extremely satisfied with their job, had patients who were also more satisfied with their health care (regression coefficient 2.10; $95 \%$ confidence interval $0.73-3.48$ ) as well as with their most recent physician consultation (regression coefficient 1.23 ; 95\% confidence interval 0.26-2.21) [11]. Moreover, the results of research of doctors satisfaction seems not to be optimistic. "Twelve percent of physicians described themselves as extremely satisfied with their work; $48 \%$, very satisfied; $34 \%$, somewhat satisfied; $5 \%$, not very satisfied; and $1 \%$, very dissatisfied" [11]. The professional guidance in choosing medical specialty could refine this percentage. There is a need of analogic studies in Poland. The results of this work suggest that there is high risk of wrong decision and low satisfaction with their future job $(71.2 \%$ of Polish students declare a problem with making this decision). That is the reason why professional guidance for medicine students is major also for their future patients.

The good example of professional guidance in choosing medical future career is Careers in Medicine published by the Association of American Medical Colleges. Students as well as doctors can find there information about salary and lifestyle, patient profiles, advice for successfully navigating the U.S. residency application and matching career self-assessments to help connect you to your preferred specialties [12]. Authors of this research find the necessity of similar help in native background.

\section{CONCLUSION}

These data are alarming in the context of the problem in opting for one medical specialty which is significant and affect the further medicine carrier. Majority of medicine students have a difficulty witch choosing medical specialty. Due to the fact that only $10 \%$ of them have already participated in classes supporting this choice and most of them have a need of guidance in this area, leading the vocational counseling is a legitimate demand. Furthermore, this work proves that it does not depend on the country or on city where the survey was conducted (results were similar). Participants of this research require support in every year of study, but in the last years of study it is more visible.

\section{Limitations of the study}

Although this research was carefully prepared, authors are still aware of its limitations and shortcomings. First of all, the population of the Polish experimental group is larger than the group of students from the other countries. This fact makes comparison difficult. Secondly, Slovenian students comprised majority of foreign student group. Authors assumed that this group is representative for other European countries too.

\section{REFERENCES}

1. Skrzypek M, Turska D. Osobowość studentów medycyny deklarujących wybór specjalizacji w zakresie chirurgii w kontekście stylu przyszłej praktyki medycznej. Prz Lek. 2015;72(6):295-301.

2. Dziubak M, Motyka M. Motywy wyboru zawodu pielęgniarki i ich uwarunkowania - badania studentów kierunku pielęgniarskiego Collegium Medicum Uniwersytetu Jagiellońskiego. Probl Piel. 2013;21(3):281-9.

3. Waszkiewicz L, Zatońska K, Einhorn J, et al. Motives for choosing medical studies by students of medical faculty at Medical University of Wroclaw. Hygeia Public Health. 2012;47(2):223-6.

4. Coutts-van Dijk LC, Bray JH, Moore S, Rogers J. Prospective study of how students' humanism and psychosocial beliefs relate to specialty matching. Acad Med. 1997;72(12):1106-8.

5. Department for Education of the United Kingdom. Counselling in schools: a blueprint for the future. Department advice for school leaders and counsellors. 2016;1-40. Available from: https://www.gov.uk/government/ uploads/system/uploads/attachment_data/file/497825/Counselling_in_ schools.pdf

6. Sringer K, Kerpelman J, Skorikov V. Career preparation: a longitudinal, process-oriented examination. J Vocat Behav. 2011;79:158-69. doi: 10.1016/j.jvb.2010.12.012.

7. Borges NJ, Savicka MI. Personality and medical specialty choice: a literature review and integration. J Career Assessment. 2002;10:362-80. doi: 10.1177/10672702010003006.

8. Petrides KV, McManus IC. Mapping medical careers: questionnaire assessment of career preferences in medical school applicants and final-year students. BMC Med Educ. 2004;1:4-18.

9. Ossai EN, Uwakwe KA, Anyanwagu UC, et al. Specialty preferences among final year medical students in medical schools of southeast Nigeria: need for career guidance. BMC Med Educ. 2016;16(1):259. Available from: https://doi.org/10.6084/m9.figshare.c.3635753.v1

10. Association of American Medical Colleges. Roadmap to residency. Understanding the process of getting into residency. 2015;1-48. Available from: http://offers.aamc.org/hubfs/AAMC_Roadmap_to_Residency. pdf?t=1489780440495

11. WY-SPE-LEK Survey (choose medical specialization). Available from: https://docs.google.com/forms/d/e/1FAIpQLSdegyx-SwC-9iGNfiEd5nYGSnjhc45RG80yXebTN79oFL0R8g/viewform?c $=0 \& w=1$

12. Diderichsen $S$, Johansson EE, Verdonk $P$, et al. Few gender differences in specialty preferences and motivational factors: across-sectional Swedish study on last-year medical students. BMC Med Educ. 2013;8(13):39. doi: 10.1186/1472-6920-13-39.

13. Mehmood SI, Khan MA, Walsh KM, Borleffs JC. Personality types and specialist choices in medical students. Med Teach. 2013;35(1):63-8. doi: 10.3109/0142159X.2012.731104. Epub 2012; 7.

14. Bittaye M, Odukogbe AT, Nyan O, et al. Medical students' choices of specialty in The Gambia: the need for career counseling. BMC Med Educ. 2012;8(12):72. doi: 10.1186/1472-6920-12-72.

15. Fang JT, Lii SC. Relationship between personality traits and choosing a medical specialty. J Formos Med Assoc. 2015;114(11):1116-21. doi: 10.1016/j.jfma.2014.05.002.

16. Curwin J. The Goo Tolerance Index: a foolproof method for choosing a medical specialty. CMAJ. 2007;177(12):1545-6. doi: 10.1503/ cmaj.071435. 
17. Bale AG, Coutinho K, Swan KG, Heinrich GF. Increasing educational indebtedness influences medical students to pursue specialization: a military recruitment potential? Mil Med. 2013;178(2):202-6.

18. Correia Lima de Souza L, Mendonça VR, Garcia GB, et al. Medical Specialty Choice and Related Factors of Brazilian Medical Students and Recent Doctors. PLoS One. 2015;24;10(7):e0133585. doi: 10.1371/journal. pone.0133585. eCollection 2015.

19. Alawad AA, Khan WS, Abdelrazig YM, et al. Factors considered by undergraduate medical students when selecting specialty of their future careers Pan Afr Med J. 2015;4(20):102. doi: 10.11604/pamj.2015.20.102.4715. eCollection 2015.

20. Atalabi MO, Adedokun BO, Agunloye A. Sociodemographic factors and clerkship experience influence Ibadan medical students' preference for radiology specialty. J Am Coll Radiol. 2013;10(6):470-4. doi: 10.1016/j. jacr.2013.01.014.

21. Mirvis DM. Choosing a medical specialty: the difference between what students want and what society needs. Isr J Health Policy Res. 2013;21;2(1):18. doi: 10.1186/2045-4015-2-18.

22. Ng-Sueng LF, Vargas-Matos I, Mayta-Tristán P, et al. Gender associated with the intention to choose a medical specialty in medical students: A cross-sectional study in 11 countries in Latin America. PLoS One. 2016;12;11(8):e0161000. doi: 10.1371/journal.pone.0161000. eCollection 2016.
Corresponding author

Dr hab. Marzena Samardakiewicz

Department of Applied Psychology, Medical University of Lublin 8 Chodźki St., 20-093 Lublin, Poland

E-mail: marzena.samardakiewicz@umlub.pl

tel: 601381092 